\title{
Response of television tower to wind load
}

\author{
Pavol Marton ${ }^{1}$ \\ ${ }^{1}$ STU Bratislava, Faculty of Civil Engineering, Department of Structural Mechanics, \\ Radlinského 11, SK-813 68 Bratislava, Slovakia
}

\begin{abstract}
This paper presents an analysis of the response of television tower to wind load. Computational model of tower is a model with the mass concentrated in the center of gravity of each part of the tower. The values of wind pressure were obtained using a record of wind speed.
\end{abstract}

\section{Introduction}

Reinforced concrete core of the tower consists of a rod with a square base $7 \times 7$ meters. External structure consists of a steel box columns that are above the platform and through steel beams connected with the core. In this amount of reinforced concrete construction continues and ends steel pipe, culminating in a laminate tube transmitters, which will consist of the tower. Individual platforms are woven into the reinforced concrete cores and corners hanging on a steel construction, Fig. 1.

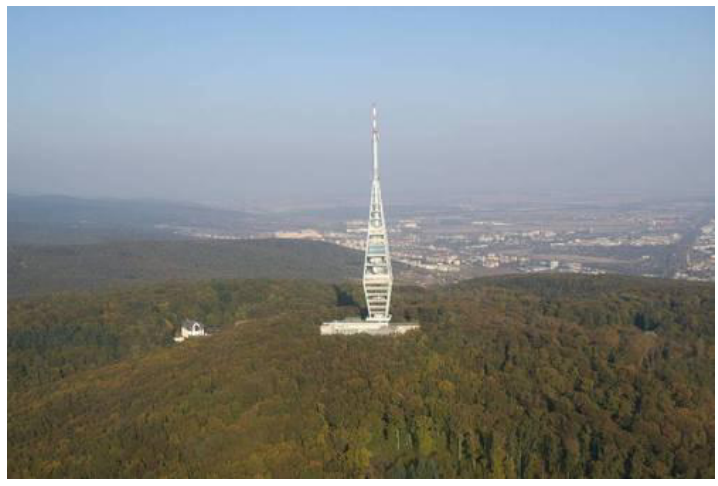

Fig. 1. The television tower.

\section{Computational model of supporting tower}

The dynamic model of the tower is a system of concentrated masses in selected centers of mass of the tower [1]. Static computational model contains a reinforced concrete rod in the core of tower, steel platformy nad rods (box columns), steel and laminate tube.

To the level of $130 \mathrm{~m}$ are located platforms and reinforcing rod, Fig. 2a. Static computational model is shown in Fig. 2b, the dynamic Fig. 2c. 

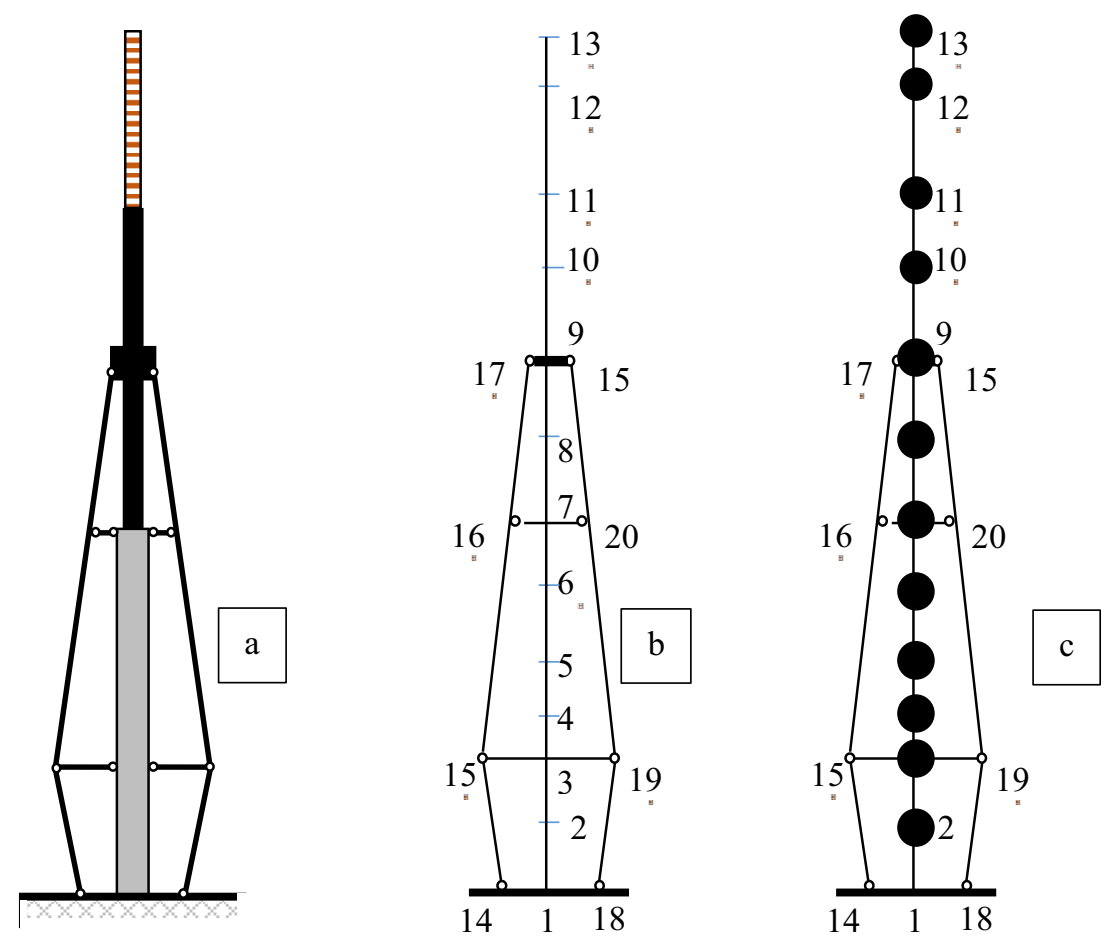

Fig. 2. Computational model of the tower.

\section{Quasi-static calculation of the response of the tower}

Modeling the wind speed is simulated by course with discrete time interval $\Delta t$. Wind pressure $w(t)$ is depending on the wind speed stated by the generally valid relation for laminar flow

$$
w(t)=c A q(t)=c A \frac{v^{2}(t)}{16}
$$

Displacement due to the load impulse is given by

$$
u(t)=w(\tau) W(t-\tau) \mathrm{d} \tau
$$

where $W(t)$ is an influence function that is the response of systems with one degree of freedom to the unit impulse

$$
W(t)=\frac{e^{-\delta \omega_{0} t}}{m \sqrt{1-\xi^{2}} \omega_{0}} \sin \sqrt{1-\xi^{2}} \omega_{0} t
$$

Displacement in time $\tau=k \Delta t$ and $t=j \Delta t$ is 


$$
u_{j}=\sum_{k=1}^{k=j-1} w_{k} W[(j-k) \Delta t]
$$

where $W(t-\tau)=W[(j-k) \Delta t]$

After the substitution, the elastic force in system with one degree of freedom after a single transformation is defined by the formula

$$
F_{j}=2 \pi \kappa \sum_{k=1}^{k=j-1} w_{k} \mathrm{e}^{-\delta \kappa(j-k)} \sin 2 \pi \kappa(j-k)
$$

where $\delta$ is the logarithmic decrement.

\section{Methodology of processing record wind speeds}

In methodology following assumptions are valid:

a) continuous chart recording wind speed is substituted by a discrete step system [2]

b) discrete values of wind speed shall be determined by discrete pressure values based on the unit area of wind $c \cdot A=1$

c) the pressure values were averaged and represent the static value of wind pressure $q_{s}$

d) the relation $w_{d}=w-w_{s}$ determines the maximum value of the dynamic component

e) dynamic wind pressure will be standardized $q_{d} / q_{d, \max } \leq 1$

f) the relative value of dynamic load is defined by the relation

$$
\frac{F_{j}}{F_{j k, \max }}=2 \pi \kappa \sum_{k=1}^{k=j-1} \frac{q_{d k}}{q_{d, \max k}} \mathrm{e}^{\delta \kappa(j-k)} \sin 2 \pi(j-k)
$$

g) the dynamic coefficient of increase in wind pressure (dynamic factor) is defined by the relation

$$
\beta=\max \frac{F_{j}}{F_{j, \max }}-1
$$

h) impact factor is related to the maximum wind pressure resulting from the relation

$$
\beta=1+\beta \frac{q_{d, \max }}{q_{\max }}
$$
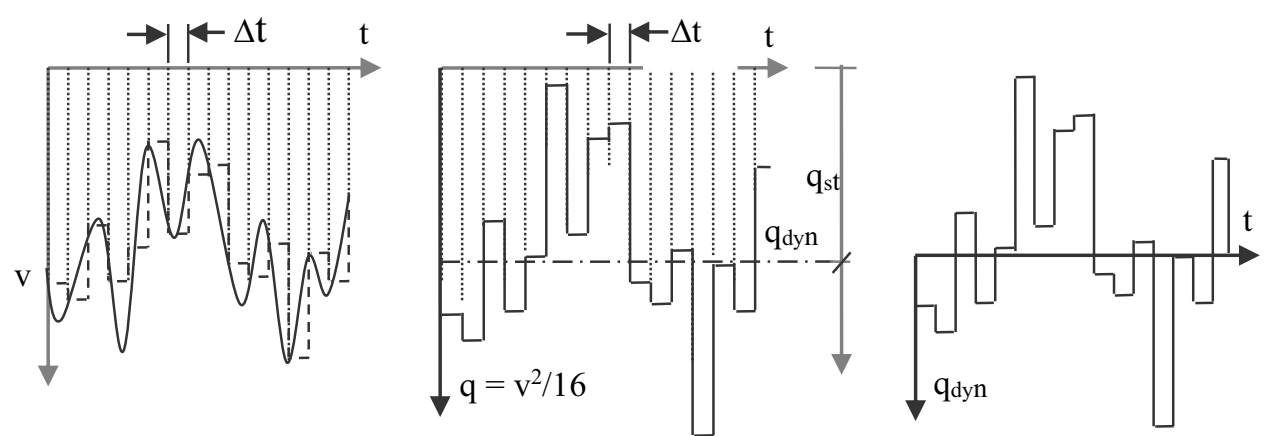

Fig. 3. Substitution of continuous recording of speed and wind pressure by the discrete one. 
i) for producing the sum of equations (6) it is appropriate to limit the correlation length of $t_{w}$

$$
t_{w}=t-\tau=(j-k) \Delta t=m \Delta t
$$

\subsection{Analysis of wind speed record}

Wind speed record [3] during a severe storm recorded maximum wind speed $v=45 \mathrm{~m} / \mathrm{s}$. Wind speed record was taken in a period of about 9 minutes. The speed record of 30 values per minute corresponding to the time interval is in Fig. 4.

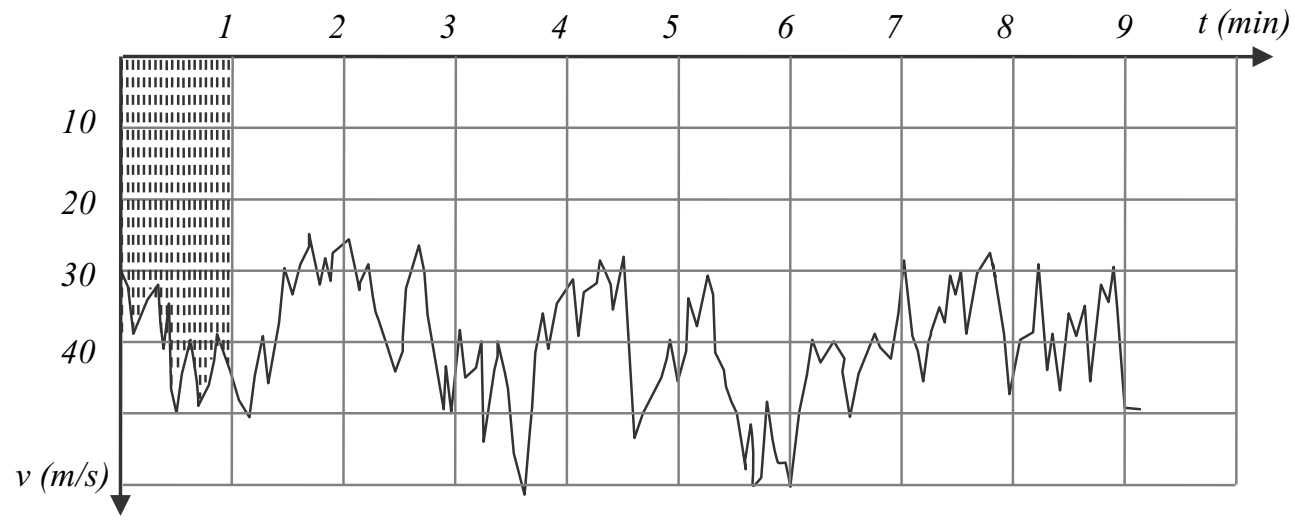

Fig. 4. Wind speed record.

a) Determination of mean and maximum dynamic components of the wind pressure Fig. 4 is in Table 1.

Table 1. Static and dynamic share stress.

\begin{tabular}{|c|c|c|c|c|}
\hline$q_{s}\left[\mathrm{kNm}^{-2}\right]$ & $q_{d, \max }\left[\mathrm{kNm}^{-2}\right]$ & $q_{\max }\left[\mathrm{kNm}^{-2}\right]$ & $q_{s} / q_{\max }$ & $q_{d, \max } / q_{\max }$ \\
\hline 0.588 & 0.458 & 1.046 & 0.56 & 0.44 \\
\hline
\end{tabular}

b) Determination of mean and maximum dynamic components of the wind pressure is in Table 2. It indicates maximum load ratio for different values of logarithmic decrement and vibration period of the non-damped natural vibration.

Table 2. Determination of mean and maximum dynamic components.

\begin{tabular}{|c|c|c|c|c|c|}
\hline \multirow{2}{*}{$\delta$} & \multicolumn{5}{|c|}{$T_{0}[\mathrm{~s}]$} \\
\cline { 2 - 6 } & 0.5 & 1.0 & 2.0 & 3.3 & 5.0 \\
\hline 0.150 & 0.413 & 0.829 & 0.852 & 1.430 & 1.717 \\
\hline 0.075 & 0.413 & 0.867 & 0.971 & 1.593 & 1.957 \\
\hline 0.025 & 0.406 & 0.883 & 1.661 & 2.028 & 2.496 \\
\hline
\end{tabular}


c) Determination of the gust dynamic coefficient

Gust factor $\varphi$ is determined for $T_{0}=3.5 \mathrm{~s}$ and the logarithmic decrement $\delta=0.15$.

Table 3. Calculation of the gust factor $\varphi$.

\begin{tabular}{|c|c|c|c|c|c|}
\hline$\varphi$ & \multicolumn{5}{|c|}{$T_{0}[\mathrm{~s}]$} \\
\hline$\delta$ & 0.5 & 1.0 & 2.0 & 3.3 & 5.0 \\
\hline 0.150 & 0.732 & 0.925 & 0.935 & 1.189 & 1.315 \\
\hline 0.125 & 0.735 & 0.926 & 0.943 & 1.218 & 1.329 \\
\hline 0.100 & 0.738 & 0.927 & 0.952 & 1.242 & 1.353 \\
\hline 0.075 & 0.742 & 0.941 & 0.987 & 1.261 & 1.421 \\
\hline 0.050 & 0.743 & 0.938 & 1.010 & 1.328 & 1.524 \\
\hline 0.025 & 0.739 & 0.959 & 1.291 & 1.452 & 1.658 \\
\hline
\end{tabular}

\subsection{Numerical calculation}

The load was calculated from the blast effects of wind calculated. Mechanical parameters and geometrical characteristics of the tower are shown in Table 4.

Table 4. Mechanical and geometrical characteristics of the tower.

\begin{tabular}{|c|c|c|c|c|c|c|c|c|}
\hline No. & $m^{*}$ & $l$ & $E I$ & No. & $m$ & No. & $l$ & $E I$ \\
\hline- & $\mathrm{kg} \cdot 10^{3}$ & $\mathrm{~m}$ & $\mathrm{~N} \cdot \mathrm{m}^{2}$ & - & $\mathrm{kg} \cdot 10^{3}$ & - & $\mathrm{m}$ & $\mathrm{N} \cdot \mathrm{m}^{2} \cdot 10^{10}$ \\
\hline 1 & 496 & 32.8 & $5.104 \cdot 10^{9}$ & 11 & 48 & 11 & 20.5 & $0.025 \cdot 10^{9}$ \\
\hline 2 & 1236 & 15.6 & $6.268 \cdot 10^{9}$ & 12 & 27 & 12 & 10 & $0.024 \cdot 10^{9}$ \\
\hline 3 & 1100 & 5.4 & $6.737 \cdot 10^{9}$ & 13 & & & & \\
\hline 4 & 838 & 9.4 & $6.260 \cdot 10^{9}$ & 14 & & & & \\
\hline 5 & 1606 & 16.2 & $5.555 \cdot 10^{9}$ & 15,19 & & & & \\
\hline 6 & 1157 & 13.5 & $4.853 \cdot 10^{9}$ & 16,20 & & & & \\
\hline 7 & 326 & 21.6 & $0.555 \cdot 10^{9}$ & 17,21 & & & & \\
\hline 8 & 166 & 19.4 & $0.158 \cdot 10^{9}$ & & & & & \\
\hline 9 & 75 & 19.3 & $0.036 \cdot 10^{9}$ & & & & & \\
\hline 10 & 60 & 19.2 & $0.021 \cdot 10^{9}$ & & & & & \\
\hline
\end{tabular}


The calculation of load forces from the blast effects of wind is shown in Table 5 .

Table 5. Load characteristics.

\begin{tabular}{|c|c|c|c|c|c|c|c|c|c|}
\hline Sec. & $l$ & $b$ & $c_{f, 0}$ & $c_{f}$ & $A_{\mathrm{ref}}(z)$ & $w_{p}(z)$ & $F_{i}$ & $\varphi$ & $F_{i}$ \\
\hline 1 & 16.2 & $\begin{array}{c}18.0 \\
4.0\end{array}$ & 15.6 & 1.19 & 73 & 161 & 644 & 1.2 & 773 \\
\hline 2 & 15.6 & $\begin{array}{c}25.7 \\
4.0\end{array}$ & 15.6 & 1.19 & 408 & 161 & 644 & 1.2 & 773 \\
\hline 3 & 5.4 & $\begin{array}{c}32,7 \\
4.0\end{array}$ & 5.4 & 1.24 & 343 & 161 & 564 & 1.2 & 677 \\
\hline 4 & 9.4 & $\begin{array}{c}30.5 \\
4.0\end{array}$ & 9.4 & 1.28 & 226 & 151 & 459 & 1.2 & 551 \\
\hline 5 & 16.2 & $\begin{array}{c}27.6 \\
4.0\end{array}$ & 16.2 & 1.33 & 353 & 156 & 490 & 1.2 & 588 \\
\hline 6 & 13.5 & $\begin{array}{c}22.6 \\
4.0\end{array}$ & 13.5 & 1.42 & 335 & 167 & 602 & 1.2 & 722 \\
\hline 7 & 21.6 & $\begin{array}{c}17.6 \\
3.0\end{array}$ & 21.6 & 1.52 & 309 & 179 & 269 & 1.2 & 323 \\
\hline 8 & 19.4 & $\begin{array}{c}11.5 \\
3.0\end{array}$ & 19.4 & 1.0 & 236 & 94 & 100 & 1.2 & 120 \\
\hline 9 & 19.3 & $\begin{array}{c}5.4 \\
3.0\end{array}$ & 19.3 & 1.2 & 58 & 14 & 336 & 1.2 & 403 \\
\hline 10 & 19.2 & 3.0 & 19.2 & 1.2 & 58 & 94 & 100 & 1.2 & 120 \\
\hline 11 & 20.5 & 2.6 & 20.5 & 1.2 & 59 & 14 & 168 & 1.2 & 202 \\
\hline 12 & 10 & 2.6 & 10 & 1.2 & 46 & 14 & 84 & 1.2 & 101 \\
\hline 13 & 5 & 2.6 & 10 & 1.2 & 13 & 14 & 41 & 1.2 & 50 \\
\hline
\end{tabular}

\section{Conclusion}

The present method of determining the effects of blast wind upon structures is applicable to support systems, such as antenna masts, towers, bridges and civil buildings.

\section{References}

1. P. Marton, Dynamic investigation of poles in the system of power lines (ES SVŠT, 1979)

2. Ch. Petersen, Anchored masts and chimneys (W.E\&S. 1970)

3. F. Steiger, Measurement of wind speed on the antenna mast, Stahlbau 34 (2008) 